\title{
Effects of CLIL on EAP Learners: Based on Sample Analysis of Doctoral Students of Science
}

\author{
Guizhen Gao \\ School of Foreign Languages and Literature, Dalian University of Technology, 2 Ling Gong Road, Dalian 116024, Liaoning Province, China \\ E-mail: guizheng@dlut.edu.cn \\ Jixin Cao (Corresponding author) \\ School of Foreign Languages and Literature, Dalian University of Technology, 2 Ling Gong Road, Dalian 116024, Liaoning Province, China \\ E-mail: caojx330@126.com
}

Received: 17-01- 2015

Published: 01-09- 2015
Accepted: 29-03- 2015

doi:10.7575/aiac.ijalel.v.4n.5p.113
Advance Access Published: April 2015

URL: http://dx.doi.org/10.7575/aiac.ijalel.v.4n.5p.113

\begin{abstract}
In Europe most studies of Content and Language Integrated Learning (CLIL) focus on language knowledge and language skills and most studies of CLIL are carried out in primary schools and secondary schools. As for the implementation of CLIL in China, most studies are done theoretically and are carried out among undergraduates. CLIL is mainly applied in the teaching and learning of general English rather than in the teaching and learning of English for Academic Purpose (EAP). In order to have a better understanding of the effect of CLIL on EAP learners, a sample analysis is undertaken among doctoral students of science. Two kinds of instruments are adopted in this paper to conduct both quantitative and qualitative study, including two questionnaires and a series of classroom observations. The study obtains the following findings: Firstly, as CLIL is effective due to its dual-focus, it is possible to implement CLIL in EAP teaching and learning. Secondly, class activities such as group work, pair work, class presentations as well as task-based course activities such as translation, paper writing, paper analysis and rewriting practice play an important role in motivating the participants to integrate discipline content and language. Besides, the four factors of CLIL which include content, communication, culture and cognition are attached great importance to by learners. Finally, the increasing ability to integrate content and language as well as the thinking patterns and cultural awareness in EAP writing greatly contributes to the participants' further academic researches.
\end{abstract}

Keywords: Content and Language Integrated Learning (CLIL); English for Academic Purpose (EAP); effect of CLIL 1. Introduction

English for Academic Purpose is usually defined as teaching English with the aim of assisting learners' study or research in that language (Ken Hyland, 2008). Gone through a winding path in EAP field, EAP teaching is now conceived by both learners and teachers as necessary but not as something that is effective. Not all the majors have bilingual courses or disciplines in English, so many students just command English for general purpose while they cannot deal with academic English proficiently (Cai Jigang, 2010). For example, according to the doctoral candidates' degree requirements in Dalian University of Technology in China, doctoral students need to publish at least one English article in foreign periodicals (Master's and Doctoral Degrees Awarding Rules of Dalian University of Technology (revised in July, 2008)). However, most doctoral candidates do not have the ability to express their fruitful researches in English. Although CLIL is used for general English teaching and learning in some colleges, it cannot function well in learners' EAP reading and writing. According to Wang Wei, the empirical studies in this field are far from adequate to provide reliable and effective guidance in the implementation process (Wang Wei, 2013). This article which is based on the analysis of the effect of CLIL in EAP classrooms aims to discuss the questions as follows: the possibility to implement CLIL in EAP classroom where both content and language are focused and interacted mutually in Dalian University of Technology (DUT), the activities and tasks that can be used to motivate the participants to integrate their discipline content and English language with regard to the current situation of doctoral candidates' degree requirement, and the effects of CLIL on doctoral candidates' EAP development worth sustaining as long-term value in their academic researches.

\section{Literature Review}

2.1 The Concept and Definition of CLIL

According to Marsh, CLIL is an approach "encompassing any activity in which a foreign language is used as a tool in the learning of a non-language subject in which both language and the subject have a joint role" (Marsh, cited in Coyle, 2002). In China, Wang Wei proposes her argument on CLIL: in EFL contexts, the implementation of CLIL involves investigation of a wide range of variables in language learning, such as, starting age, starting linguistic level, duration and intensity, along with socio-cultural issues (Wang Wei, 2013). 


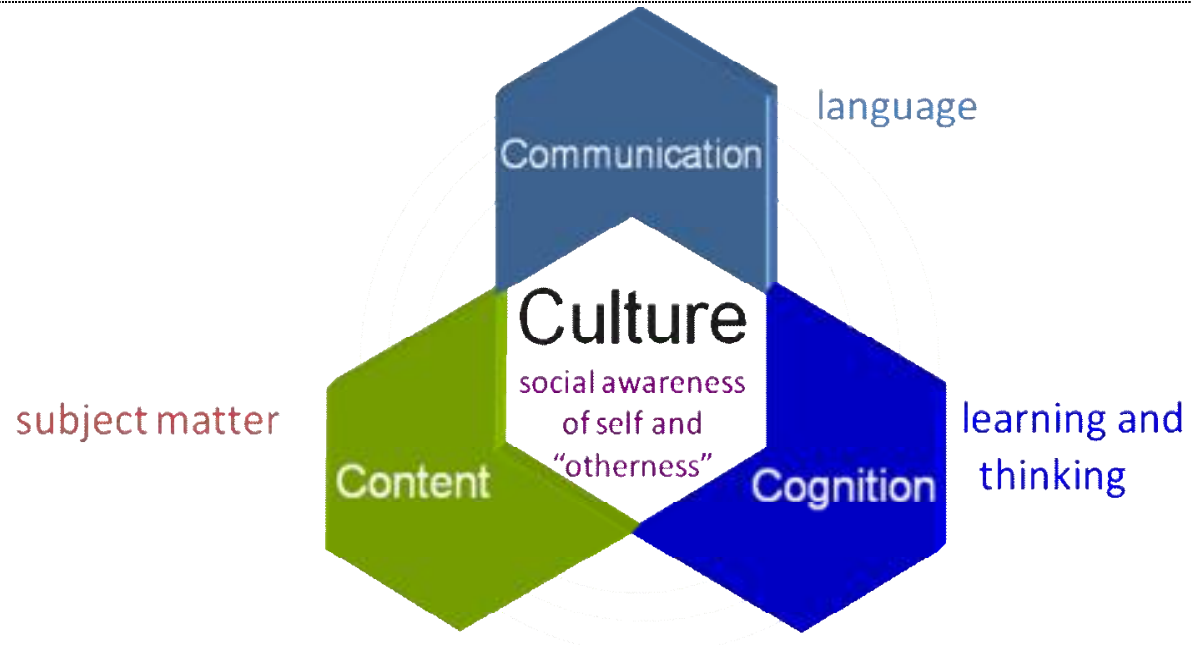

Figure 1. The CLIL 4Cs' Framework

Coyle (2007) illustrates 4Cs' framework and indicates that culture which mainly refers to social awareness of self and "otherness", content which is concerned with the discipline or subject matter, communication which refers to the target language, and cognition which refers to the ways in thinking and making sense of everything in the world, are the four core factors that underpin the successful CLIL implementation.

\subsection{Major Researches on CLIL Abroad and at Home}

Among the researches on CLIL abroad, most focus on language knowledge and language skills. The CLIL group outperforms the non-CLIL group in the production of affixal morphemes (Izaskun Villarreal \& Garcia Mayo, 2009). The methods of CLIL have a great effect on lexical depth (Espinosa, 2009). CLIL students have a significantly better performance on the cloze and receptive tests over non-CLIL students (Ruiz de Zarobe \& Jimenez Catalan, 2009). NonCLIL learners produce significantly more lexical transfer errors than their peers (Agustin Llach, 2009). CLIL learners significantly outperform non-CLIL learners in the use of placeholder (Maria Martinez Adrian \& Gutierrez Mangado, 2009). CLIL students can rehearse participation in L2-talk-in-interaction under simplified conditions because they are familiar with the context and its discourse rules (Dalton-Puffer, 2009). According to Whittaker \& LLinares, the efforts made by pupils and their teachers in spoken and written language give them a good start on the road to improved achievement, which justify the CLIL approach (Whittaker \& LLinares, 2009). In terms of the lexical competence, Ojeda Alba proposes that studies of themes and vocabulary in CLIL and non-CLIL instruction show that variables such as the socioeconomic context may have an influence on the acquisition of students' lexical competence (Ojeda Alba. 2009). By statistics, most of these studies on CLIL are concerned with language knowledge and language skills and they are carried out in primary schools and secondary schools.

In China, however, most studies are done theoretically and many studies are done on the basis of CBI (content based instruction) rather than CLIL. Most studies are carried out among undergraduate students in general English learning. Therefore, it is necessary to conduct the current research to study the effect of CLIL on EAP learners among doctoral students of science.

\section{Methodology}

In this research, both quantitative and qualitative studies are employed. Two kinds of instruments are adopted, questionnaires and classroom observations. Two questionnaires are used to investigate and analyze the problems of doctoral students' learning strategies in EAP, the effects of CLIL on the participants, and the mode of class organization they are engaged in. A series of classroom observations are made aiming to explore how the teacher organizes activities and designs tasks to motivate the students to integrate their discipline content and English language, and to testify how the tasks and activities take place in the involvement of both content and English.

The participants involved in the present research are doctoral candidates from four classes whose EAP courses are taught by the same teacher with the same teaching materials in Dalian University of Technology. They major in different fields of science. All the four classes have a 100-minute long EAP class per week and there are 9 weeks of EAP courses totally in a semester. They are taught EAP course by CLIL method. All of the participants share the similar English learning background. It is the first time for them to learn EAP systematically. They are all required to publish at least one English paper in foreign journals or periodicals before graduation of $\mathrm{PhD}$ degree.

\subsection{Questionnaires}

Two questionnaires are adopted to explore the effect of CLIL on EAP learners among doctoral students of science. The first questionnaire which is composed of 24 items is issued before the EAP course, aiming to investigate and analyze the current situation and learning problems and strategies in doctoral students' EAP learning. The second questionnaire which contains 21 items is issued at the end of the EAP course so as to examine the effects of CLIL on the participants, and the mode of class organization, as well as the teaching factors that cause the change of doctoral students' strategies and motivations in EAP learning with the implementation of CLIL. The two questionnaires were tested at the beginning in two classes of doctoral candidates who attend EAP courses with CLIL mode. The test reliability is respectively 0.745 and 0.752 . 
Doctoral students were invited to complete the survey via paper-based questionnaires distributed by their classroom teacher and the researcher. At the beginning of the investigation, the subjects were acknowledged the purpose of the questionnaires and were asked to finish the survey according to their own actual learning situation. The total number of responses collected were $n=132$ (pre), $n=134$ (post), among which 128 pre-test copies and 130 post-test copies of the questionnaires were valid and they were applied in this study. The raw data were processed and put into the computer to be analyzed by SPSS 17.0.

The analysis of the data includes the following aspects.

1) Descriptive statistics including frequencies, means, maximum scores, minimum scores, and standard deviation were computed to show the distribution of EAP learning attitudes and strategies.

2) An Independent-Sample T-Test was made to contrast the difference in EAP learning attitudes and strategies among the subjects who participated in pre-test and post-test.

\subsection{Classroom Observation}

Eight observations were conducted with the teacher instructing a typical 90-minute doctoral students' EAP class. The researcher took a role of a complete observer. An observational protocol was designed to record descriptive and reflective notes. The researcher made memos by writing primary thoughts on the margins of the note paper. Memoing the data is an initial step in deciding on codes and themes. (Creswell, 2007). Later the portraits of teachers, physical setting of classrooms, particular events and activities that happened in classrooms as well as the author's own reaction were described.

The data of observation were analyzed according to the following steps. Step1, the instructional materials received from the teacher were organized regularly for a review. Step 2, the transcripts and observation notes were checked for accuracy and the data were explored by reading through and understanding it with the purpose of developing an overall understanding of the database. During the reading and understanding process, several categories were summarized. Step 3 , labels were assigned to codes. Step 4, the researcher looked for the patterned regularities in the data and the correspondence between CLIL elements and the actual classroom instruction. Step 5, the researcher provided naturalistic generalization. Step 6, the researcher examined lesson plans as well as handouts and student worksheets used during in-class and assignment activities. Step 7, the researcher examined printed materials and ppt files that the teacher used while planning and presenting her lessons. This examination helped to see how the teacher designs meaningful, purposeful and challenging activities to help students integrate their discipline content and language.

\section{Results and Findings}

Through the descriptive analysis of the collected data, the subjects' attitudes towards EAP writing, strategies preference in EAP writing are analyzed in this chapter. Then the comparative research on the attitudes towards EAP and the strategies in EAP writing between pre-trial and post-trial is demonstrated respectively to investigate the possible difference.

\subsection{Overall summary of pre and post basic information}

\begin{tabular}{|c|c|c|c|c|c|}
\hline & & $\begin{array}{l}\text { Pre- } \\
\text { trial }\end{array}$ & & $\begin{array}{l}\text { Post- } \\
\text { trial }\end{array}$ & \\
\hline Variables & Classification & $\begin{array}{c}\text { Frequen } \\
\text { cy }\end{array}$ & $\begin{array}{l}\text { Constituent } \\
\text { ratio }(\%)\end{array}$ & $\begin{array}{c}\text { Frequen } \\
\text { cy }\end{array}$ & $\begin{array}{l}\text { Constituent } \\
\text { ratio }(\%)\end{array}$ \\
\hline \multirow[t]{2}{*}{ Gender } & male & 88 & 68.8 & 84 & 64.6 \\
\hline & female & 40 & 31.3 & 46 & 35.4 \\
\hline \multirow[t]{4}{*}{ School year } & 2013 & 98 & 76.6 & 110 & 84.6 \\
\hline & 2012 & 2 & 1.6 & 4 & 3.1 \\
\hline & 2011 & 25 & 19.5 & 16 & 12.3 \\
\hline & Before 2010 & 3 & 2.3 & & \\
\hline \multirow[t]{3}{*}{ Cultivating modes } & PhD. candidate & 14 & 10.9 & 18 & 13.8 \\
\hline & $\begin{array}{l}\text { Full-time } \\
\text { recruited }\end{array}$ & 100 & 78.1 & 102 & 78.5 \\
\hline & Other & 14 & 10.9 & 10 & 7.7 \\
\hline \multirow[t]{4}{*}{$\begin{array}{l}\text { Time used in English } \\
\text { learning }\end{array}$} & $\begin{array}{l}\text { Less than } 12 \\
\text { years }\end{array}$ & 20 & 15.6 & 20 & 15.4 \\
\hline & $12-14$ years & 60 & 46.9 & 51 & 39.2 \\
\hline & $14-16$ years & 27 & 21.1 & 32 & 24.6 \\
\hline & $\begin{array}{l}\text { More than } 16 \\
\text { years }\end{array}$ & 21 & 16.4 & 27 & 20.8 \\
\hline \multirow[t]{3}{*}{ Foreign language level } & CET 4 & 23 & 18.0 & 20 & 15.4 \\
\hline & CET 6 & 102 & 79.7 & 107 & 82.3 \\
\hline & other & 3 & 2.3 & 3 & 2.3 \\
\hline
\end{tabular}


The ages of the participants are between 22 and 43 with an average age of $26.95 \pm 3.57$ in the investigation involving Questionnaire One while they are between 22 and 45 with an average age of 27.45 \pm 3.91 involving Questionnaire Two. Other basic information is demonstrated in Chart 1. More than a half of the candidates are males both in the pre-trial research and post-trial research. Most candidates are admitted to have doctoral education in 2013.

4.2 Descriptive Analysis of Subjects' EAP Learning Attitudes and Strategies before CLIL

4.2.1 Subjects' EAP Learning Attitudes before CLIL

\begin{tabular}{|l|c|c|c|}
\hline & $\begin{array}{l}\text { 10. Attitudes towards EAP } \\
\text { writing : }\end{array}$ & $\begin{array}{l}\text { 11. Would you like to } \\
\text { attend international } \\
\text { academic conferences ? }\end{array}$ & $\begin{array}{l}\text { 12. How easy is it to write } \\
\text { scientific research in } \\
\text { English? }\end{array}$ \\
\hline Mean & 3.91 & 4.77 & 2.18 \\
\hline $\mathrm{N}$ & 128 & 128 & .736 \\
\hline $\begin{array}{l}\text { Standard } \\
\text { deviation }\end{array}$ & .553 & .425 & $49.6 \%$ \\
\hline $\begin{array}{l}\text { Percentage } \\
\text { of N }\end{array}$ & $49.6 \%$ & $49.6 \%$ & 1 \\
\hline Minimum & 1 & 4 & 4 \\
\hline Maximum & 5 & 5 & 128 \\
\hline
\end{tabular}

Chart 2. Attitudes towards EAP writing before CLIL

As shown in the data, most students which account for more than $96 \%$ percent think reading discipline-based English literature is important to scientific research. More than $99 \%$ students believe writing in English is of great importance to scientific research. About $93 \%$ of the students think improving EAP is important to them in the future development.

According to Chart 2, most doctoral students take positive attitudes towards EAP writing, and would like to attend international academic conference. However, it is difficult for them to write their scientific researches in English sufficiently.

4.2.2 Subjects’ EAP Learning Strategies before CLIL

\begin{tabular}{|c|c|c|c|c|c|}
\hline Questionnaire & Item & Often & Sometimes & Seldom & Never \\
\hline \multirow[t]{2}{*}{1} & $\begin{array}{l}\text { 13. Analyze } \\
\text { writing } \\
\text { methods: }\end{array}$ & 21 & 74 & 30 & 3 \\
\hline & & $16.4 \%$ & $57.8 \%$ & $23.4 \%$ & $2.3 \%$ \\
\hline \multirow[t]{2}{*}{1} & $\begin{array}{l}\text { 14. Analyze } \\
\text { structure } \\
\text { features: }\end{array}$ & 37 & 69 & 20 & 2 \\
\hline & & $28.9 \%$ & $53.9 \%$ & $15.6 \%$ & $1.6 \%$ \\
\hline \multirow[t]{2}{*}{1} & $\begin{array}{l}\text { 15. Imitate } \\
\text { and apply } \\
\text { sentence } \\
\text { patterns: }\end{array}$ & 57 & 49 & 17 & 5 \\
\hline & & $44.5 \%$ & $38.3 \%$ & $13.3 \%$ & $3.9 \%$ \\
\hline \multirow[t]{2}{*}{1} & $\begin{array}{l}\text { 16. Analyze } \\
\text { vocabulary } \\
\text { usage: }\end{array}$ & 22 & 73 & 29 & 4 \\
\hline & & $17.2 \%$ & $57.0 \%$ & $22.7 \%$ & $3.1 \%$ \\
\hline
\end{tabular}

Chart 3. EAP learning strategies before CLIL

As shown in Chart 3, more than half of the subjects just analyze writing methods, structure features and vocabulary of literature "sometimes". $44.5 \%$ of the subjects are apt to imitate and apply EAP sentence patterns frequently. Therefore, among the four strategies, imitating and applying EAP sentence patterns significantly outstrips the other three strategies and becomes the most frequently used one. Thus, it can be concluded that most students prefer to attach importance to sentence writing and ignore the microscopic structure and specific details in vocabulary usage. 
4.3 Analysis of Subjects' EAP Learning Attitudes and Strategies after CLIL

4.3.1 Subjects' EAP Learning Attitudes after CLIL

\begin{tabular}{|l|c|c|c|}
\hline & $\begin{array}{l}\text { 10. Attitudes towards EAP } \\
\text { writing : }\end{array}$ & $\begin{array}{l}\text { 11. Would you like to } \\
\text { attend international } \\
\text { academic conferences ? }\end{array}$ & $\begin{array}{l}\text { 12. How easy is it to write } \\
\text { scientific research in } \\
\text { English? }\end{array}$ \\
\hline Mean & 4.18 & 4.66 & 2.02 \\
\hline $\mathrm{N}$ & 130 & 130 & 130 \\
\hline $\begin{array}{l}\text { Standard } \\
\text { deviation }\end{array}$ & .590 & .604 & .498 \\
\hline $\begin{array}{l}\text { Percentage } \\
\text { of N }\end{array}$ & $50.4 \%$ & $50.4 \%$ & $50.4 \%$ \\
\hline Minimum & 3 & 2 & 1 \\
\hline Maximum & 5 & 5 & 4 \\
\hline
\end{tabular}

Chart 4. EAP learning attitudes after CLIL

After EAP course with CLIL, most doctoral students possess more positive attitudes towards EAP writing, and still would like to attend international academic conferences. However, it is still difficult for them to write their scientific researches in English sufficiently. Therefore, EAP course with CLIL does not decrease too much difficulty that the students feel in EAP writing.

4.3.2 Subjects' EAP Learning Strategies after CLIL

\begin{tabular}{|l|l|c|c|c|c|}
\hline Questionnaire & \multicolumn{1}{|c|}{ Item } & often & sometimes & seldom & Never \\
\hline 2 & $\begin{array}{l}13 . \text { Analyze } \\
\text { writing } \\
\text { methods: }\end{array}$ & 40 & 73 & 14 & 3 \\
\hline & & $30.8 \%$ & $56.2 \%$ & $10.8 \%$ & $2.3 \%$ \\
\hline 2 & $\begin{array}{l}14 . \text { Analyze } \\
\text { structure } \\
\text { features: }\end{array}$ & 53 & 65 & 9 & 3 \\
\hline 2 & $\begin{array}{l}15 . \text { Imitate } \\
\text { and apply } \\
\text { sentence } \\
\text { patterns: }\end{array}$ & 78 & 43 & 5 & $2.8 \%$ \\
\hline 2 & $\begin{array}{l}16 . \text { Analyze } \\
\text { vocabulary } \\
\text { usage: }\end{array}$ & 50 & 62 & 13 & $4.3 \%$ \\
\hline & & $38.5 \%$ & $47.7 \%$ & $10.0 \%$ & $3.8 \%$ \\
\hline
\end{tabular}

Chart 5. EAP learning strategies after CLIL

As shown in Chart 5, 87\% of the subjects have the awareness and habits to analyze writing method of literature, $90.8 \%$ have the awareness to analyze the structure features of literature, $93.1 \%$ are apt to imitate and apply EAP sentence patterns, and $86.2 \%$ are aware of the vocabulary usage skills. Among the most frequently used strategies, imitating and applying EAP sentence patterns which accounts for $60 \%$ is still the top one. Compared with the statistics in Chart 3, it can be concluded that most students have the tendency to develop the four strategies to be their habits in EAP writing after the EAP course with CLIL.

\subsubsection{The Effect of CLIL}

4.3.3.1 Effective activities and tasks that motivate the participants to integrate their discipline content and English language

In order to figure out the effective activities and tasks that motivate the participants to integrate their discipline content and language, the following bar charts are presented. 


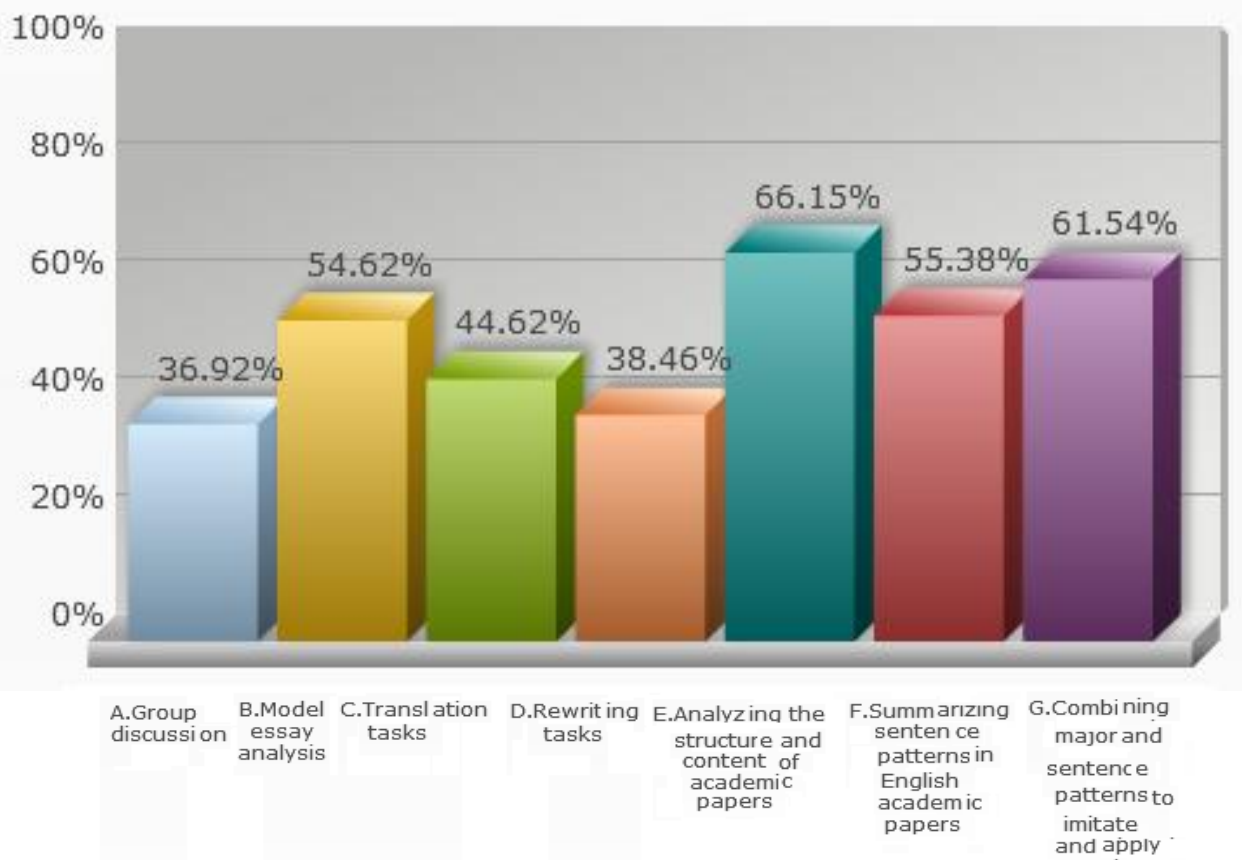

Figure 2. Course Activities Motivate the Students to Integrate Discipline Content and Language

From the figures in Figure 2, all the seven course activities have the function to motivate students to integrate their discipline content and language. Analyzing the structure and content of academic papers is the top course activity which motivates the students to integrate discipline content and English language, followed by combining major and sentence patterns to imitate and apply. Besides, group discussion and rewriting tasks account for less than other activities in the process.

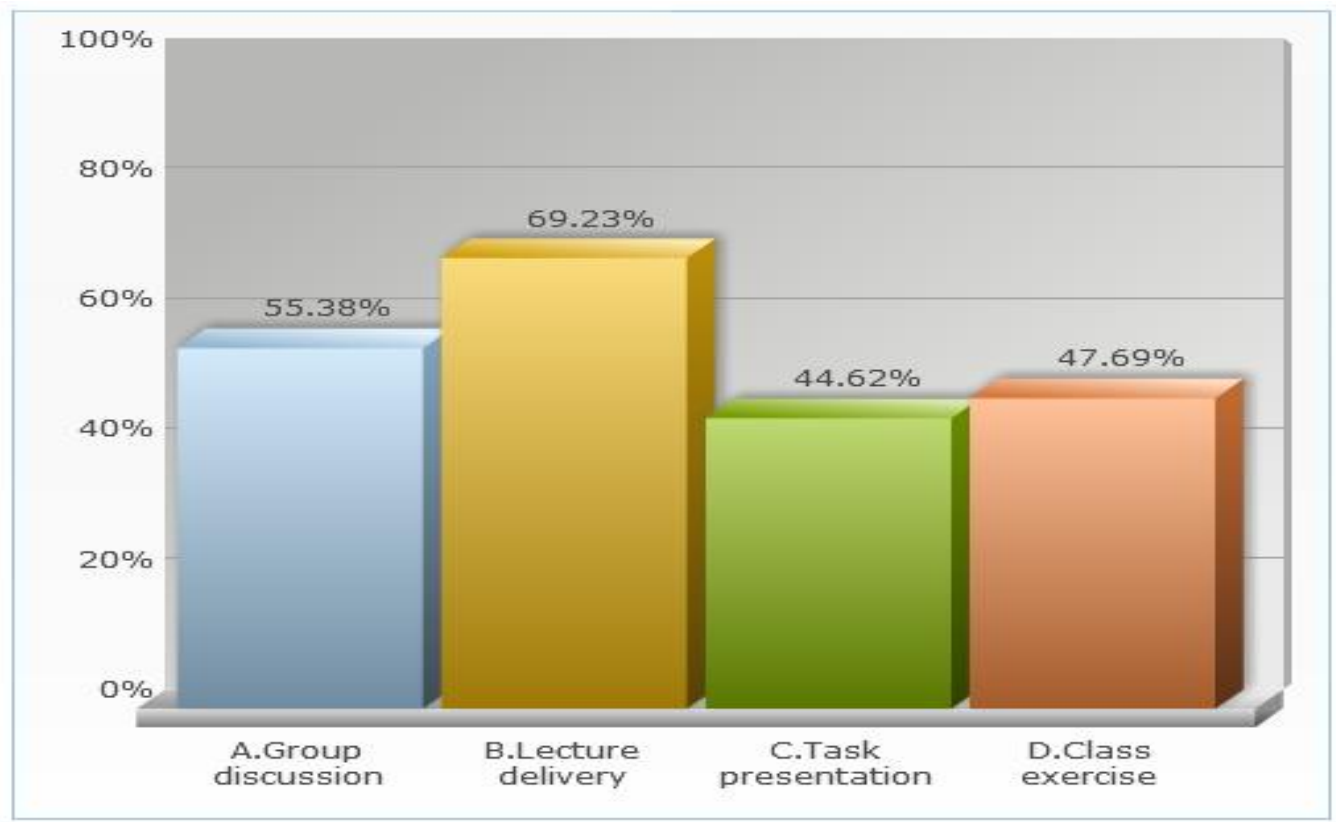

Figure 3. Class Organization Patterns That the Subjects Are Interested in

As for the four kinds of class organization patterns, they share certain percentage and attract a certain amount of students. Group discussion and lecture delivery are the most popular class organization patterns.

4.3.3.2 The long-term value of CLIL on doctoral candidates' EAP development

In order to investigate the effect of CLIL on doctoral candidates' EAP development worth sustaining as long-term value in academic researches, 11 items are designed in Questionnaire Two. 


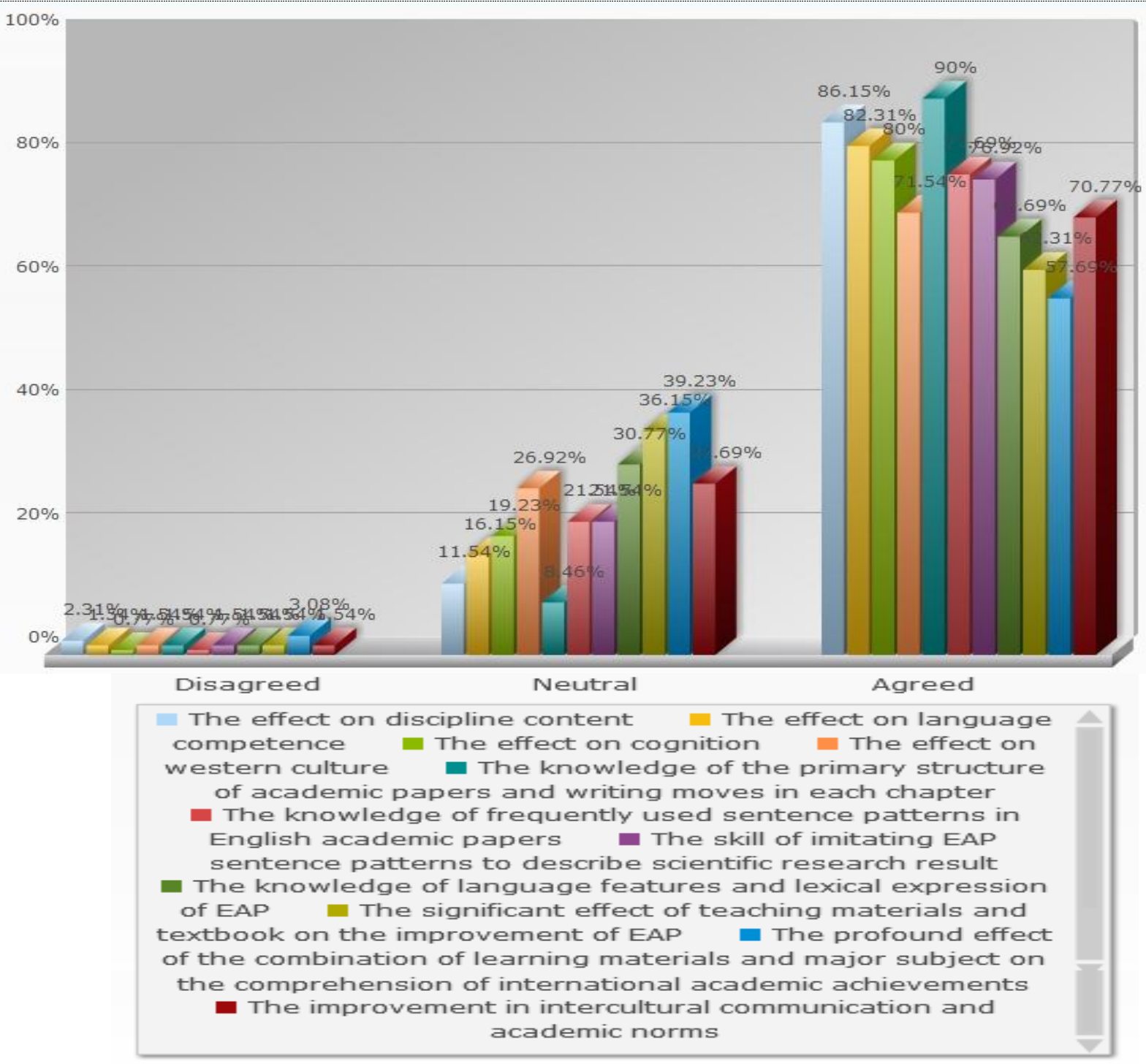

Figure 4. The Effect of CLIL on Doctoral Candidates' EAP Development

As shown in Figure 4, acquiring knowledge of the primary structure of academic papers and writing moves in each chapter is the most influential factor, followed by the effect on discipline content, language competence, and cognition, which respectively accounts for no less than $80 \%$.

Therefore, CLIL approach is successful and helps to improve students' foreign language competence. CLIL is an effective way to learn discipline content. It not only helps students to understand other cultures better, but also helps to motivate students to think differently.

\subsection{Comparative Researches}

4.4.1 Overall summary of pre and post attitude responses

\begin{tabular}{|c|c|c|c|c|}
\hline Items & & $\begin{array}{l}\text { Pre- } \\
\text { trial }\end{array}$ & $\begin{array}{c}\text { Post- } \\
\text { trial }\end{array}$ & Total \\
\hline \multirow{2}{*}{ A. contribute in international conference and journals } & Number & 99 & 113 & 212 \\
\hline & Percentage & $77.3 \%$ & $86.9 \%$ & \\
\hline \multirow{2}{*}{ B. join international academic exchange programs } & Number & 57 & 60 & 117 \\
\hline & Percentage & $44.5 \%$ & $46.2 \%$ & \\
\hline \multirow{2}{*}{ C. meet the requirements for academic degree } & Number & 65 & 57 & 122 \\
\hline & Percentage & $50.8 \%$ & $43.8 \%$ & \\
\hline \multirow{2}{*}{ D. read English research papers } & Number & 71 & 77 & 148 \\
\hline & Percentage & $55.5 \%$ & $59.2 \%$ & \\
\hline \multirow{2}{*}{ E. write English abstract } & Number & 104 & 80 & 184 \\
\hline & Percentage & $81.3 \%$ & $61.5 \%$ & \\
\hline Total & Number & 128 & 130 & 258 \\
\hline
\end{tabular}

Chart 6. The purposes for EAP course and the beneficial aspects of EAP 
As for the participants' purposes for taking EAP course, those who want to contribute in international conferences and journals accounts for $77.3 \%$, those who want to join international academic exchange programs accounts for $44.5 \%$, those who want to meet the requirements for academic degree accounts for $50.8 \%$, those who aim to read English research papers accounts for 55.5\%, and those who aim at English abstract accounts for 81.3\%. After the EAP course with CLIL, participants were asked to check out in what aspects EAP is helpful for them. The result shows that EAP helps a lot in item A, B, D.

\begin{tabular}{|ccccc|}
\hline Items & & $\begin{array}{c}\text { Pre- } \\
\text { trial }\end{array}$ & $\begin{array}{c}\text { Post- } \\
\text { trial }\end{array}$ & Total \\
\hline vocabulary deficiency & Number & 87 & 75 & 162 \\
& Percentage & $68.0 \%$ & $57.7 \%$ & \\
structure unfamiliarity & Number & 49 & 47 & 96 \\
& Percentage & $38.3 \%$ & $36.2 \%$ & 142 \\
different thinking patterns & Number & 60 & 82 & 92 \\
& Percentage & $46.9 \%$ & $63.1 \%$ & \\
culture difference & Number & 30 & 62 & 258 \\
\hline
\end{tabular}

Chart 7. The difficulties in searching for and reading English literature

In terms of the difficulties for the participants in searching and reading English literature, there is significant decrease in deficient vocabulary and unfamiliar structure. Difficulties in thinking pattern and culture difference become more obvious after EAP course. Among the four kinds of difficulties, vocabulary deficiency and different thinking patterns are the most important ones in the research both before and after the EAP course.

\begin{tabular}{|c|c|c|c|c|}
\hline Items & & $\begin{array}{l}\text { Pre- } \\
\text { trial }\end{array}$ & $\begin{array}{c}\text { Post- } \\
\text { trial }\end{array}$ & Total \\
\hline \multirow{2}{*}{ Grammar } & Number & 62 & 58 & 120 \\
\hline & Percentage & $48.4 \%$ & $45.3 \%$ & \\
\hline \multirow{2}{*}{ Tense } & Number & 34 & 32 & 66 \\
\hline & Percentage & $26.6 \%$ & $25.0 \%$ & \\
\hline \multirow{2}{*}{ Modes of expression } & Number & 86 & 90 & 176 \\
\hline & Percentage & $67.2 \%$ & $70.3 \%$ & \\
\hline \multirow{2}{*}{ Thinking patterns } & Number & 80 & 85 & 165 \\
\hline & Percentage & $62.5 \%$ & $66.4 \%$ & \\
\hline Total & Number & 128 & 128 & 256 \\
\hline
\end{tabular}

Chart 8. The difficulties in writing academic papers in English

The difficulties in writing academic papers in English can be shown in Chart 8. Among the four kinds of difficulties in writing academic papers, the percentage of tense is the lowest $(26.6 \%$ and $25 \%)$, followed by grammar $(48.4 \%$ and $45.3)$, mode of expression $(67.2 \%$ and $70.3 \%)$ and thinking patterns $(62.5 \%$ and $66.4 \%)$. On the whole, mode of expression receives the highest percentage in both pre-test and post-test, while tense problem receives the lowest. It can be concluded that doctoral students of science show greater tendency in feeling difficult in mode of expression and thinking patterns during the process of academic writing.

In order to obtain further insights into the students' learning attitudes preference, Independent-Sample T-test is applied to figure out whether there is possible difference in learning attitudes towards EAP between pre-test and post-test. The statistic figures are shown in the following chart.

\begin{tabular}{|c|c|c|c|c|c|c|}
\hline Items & $\begin{array}{c}\text { Questi } \\
\text { onnair } \\
\text { e }\end{array}$ & $\mathrm{N}$ & Mean & Std. Deviation & $t$ & $P$ \\
\hline \multirow[t]{2}{*}{ 10. Attitudes towards EAP writing : } & 1 & 128 & 3.91 & .553 & \multirow[t]{2}{*}{3.892} & .000 \\
\hline & 2 & 130 & 4.18 & .594 & & \\
\hline \multirow{2}{*}{$\begin{array}{l}\text { 11. Would you like to attend international academic } \\
\text { conference? }\end{array}$} & 1 & 128 & 4.77 & .425 & \multirow[t]{2}{*}{1.598} & .111 \\
\hline & 2 & 130 & 4.66 & .604 & & \\
\hline \multirow{2}{*}{$\begin{array}{l}\text { 12. How difficult is it to write scientific research in } \\
\text { English? }\end{array}$} & 1 & 128 & 2.18 & .736 & \multirow[t]{2}{*}{2.102} & .036 \\
\hline & 2 & 130 & 2.02 & .498 & & \\
\hline
\end{tabular}

Chart 9. Comparison of learning attitudes towards EAP among learners tested before and after EAP course with CLIL 
It can be found in the following chart that the test reveals difference that is significant at the 0.05 level in the aspects of item $10(\mathrm{p}<0.05)$ and item $12(\mathrm{p}<0.05)$.

4.4.2 Overall summary of pre and post EAP writing strategies responses

Independent-Sample T-test is used to analyze the difference in the use of each strategy in Questionnaire One and Questionnaire Two among the students. The results of comparisons are shown in Chart 10.

\begin{tabular}{|c|c|c|c|c|c|c|}
\hline Items & $\begin{array}{c}\text { Questi } \\
\text { onnair } \\
\text { e }\end{array}$ & $\mathrm{N}$ & Mean & Std. Deviation & $t$ & $P$ \\
\hline \multirow[t]{2}{*}{ 13. Analyze writing methods : } & 1 & 128 & 3.63 & 1.079 & \multirow[t]{2}{*}{$3 . \overline{4} 48$} & \multirow[t]{2}{*}{.001} \\
\hline & 2 & 130 & 4.06 & .913 & & \\
\hline \multirow{2}{*}{ 14. Analyze structure features } & 1 & 128 & 3.94 & 1.018 & \multirow[t]{2}{*}{2.842} & .005 \\
\hline & 2 & 130 & 4.26 & .803 & & \\
\hline \multirow[t]{2}{*}{ 15. Imitate and apply sentence patterns : } & 1 & 128 & 4.06 & 1.155 & \multirow[t]{2}{*}{$\begin{array}{c}- \\
2.831\end{array}$} & .005 \\
\hline & 2 & 130 & 4.43 & .923 & & \\
\hline \multirow{2}{*}{ 16. Analyze vocabulary usage : } & 1 & 128 & 3.61 & 1.117 & \multirow[t]{2}{*}{$\begin{array}{c}- \\
3.611\end{array}$} & .000 \\
\hline & 2 & 130 & 4.09 & 1.030 & & \\
\hline \multirow{2}{*}{ 17. The methods used: } & 1 & 128 & 1.53 & .627 & \multirow[t]{2}{*}{1.796} & .074 \\
\hline & 2 & 130 & 1.39 & .616 & & \\
\hline \multirow[t]{2}{*}{ 18. How to organize academic papers' structure? } & 1 & 128 & 1.94 & .392 & \multirow[t]{2}{*}{$\overline{-} . \overline{155}$} & .032 \\
\hline & 2 & 130 & 2.05 & .471 & & \\
\hline
\end{tabular}

Chart 10. Comparison analyses in EAP writing strategies among learners tested before and after EAP course with CLIL

From the chart, it can be found that the test reveals difference that is significant at the 0.05 level in the aspects of item $13(\mathrm{p}<0.05), 14(\mathrm{p}<0.05), 15(\mathrm{p}<0.05), 16(\mathrm{p}<0.05)$, and $18(\mathrm{p}<0.05)$. The means of item 13,14, 15, 16 increased from the values in pre-test to those in the post-test, which indicates that CLIL contributes to the strategy utilization in EAP writing and the effects of these four aspects worth sustaining as long-term value in doctoral students' academic researches.

\subsection{Classroom Observation}

The observations were implemented in Room 518 in Teaching Building for Postgraduates of DUT. The classroom was appropriate in size to contain all the students with large windows on the side. Desks were arranged row by row to allow 8 students to be seated in each row.

1) In the initial class

The teacher identified the course introduction as well as the objectives of the EAP course for the doctoral students and required that the students should be seated in groups of 5 by their own volition so as to do discussions conveniently. Then the teacher's main self-information and contact ways were given to the students.

After a brief introduction of the objectives, the evaluation or assessment method was presented. The students were asked to cover the class performance which accounts for $15 \%$, the assignment which accounts for $55 \%$, and the final exam which accounts for $30 \%$.

2) The teaching process of each class

At the beginning of each main part of EAP writing, the teacher presented aims and objectives firstly to make the students have certain leaning aims. In the introduction part of the course, the teacher asked several warm-up questions to arouse students' motivation and interest in learning. Questions such as "What is a research paper?" "What do you mean by scientific research methods?" "How should we do scientific research work?" are good examples to demonstrate class discussions and critical thinking. In the title writing part, the teacher asked the students to think about the title's main factors that the students may have never thought about with questions such as "What is in a title". In the introduction writing part, students were asked to think about what the purpose of the introduction is to a dissertation/thesis and what the researcher should write in the introduction section. As for literature review writing, the definition of literature review, the purposes of literature review and the appropriate methods to write literature review were asked to think about. In terms of results and discussion part, the students were required to think about how to present results in their researches, how to make comments on the results, what to present in the part of results, what to comment on the results. 
In terms of the course demonstration, it can be divided into three parts or steps. At the beginning, the topic was introduced by warming-up questions. Next, the course was organized by various class tasks and activities. Group discussions about certain questions were related to certain part of the teaching plan. The teacher encouraged the students to share their opinions and understanding followed by an authoritative explanation given by experts. Definition and clarification features and functions of different parts in a dissertation were listed and explained. Stages and steps of each part's EAP writing as well as examples were presented to help the students to have a clear understanding. Inevitable, normative requirements of each part and useful expressions and sentence patterns were listed for reference. Tasks included translation, generalization, and rewriting. Besides, there was reference recommendation for the students to have further understanding and learning. As soon as the course of each part came to an end, the teacher would make some comments, summarize the course content and emphasize key points.

The delivery of each course was demonstrated at appropriate pace. Time allocation was reasonable and the method to integrate language and discipline content shared more time. The text book is named Task-based EAP Writing. The examples and tasks were designed on the basis of paragraphs selected from international journals for the students to analyze and learn from. Language usage was also laid great importance as sentence patterns were excerpted from international journals. By raising their language awareness, the students can creatively and conscientiously use the sentence patterns in their own EAP writing.

Tasks and class activities were assigned according to the concrete content of each part. For example, in the introduction part, the students were asked to write an introduction of about 150-200 words according to the specified information and hand it in. Group members were asked to discuss the outline and think about sentence patterns that can be used in each aspect. The topic was "A Cover for the SPPPV" which is closely related to students' discipline or major. In order to integrate content and language naturally, the students were led to integrate the content with certain sentence patterns and introduction structure. The students imitated and followed sentence patterns that can be used in introduction writing and finished the writing tasks naturally. In the translation tasks, the sentences were also selected from international discipline-related periodicals which involve different majors or fields of science.

Either in the lecture delivery process or in the task fulfillment, the teacher tried to motivate the students' cognition and culture awareness. Students were reminded to think and discuss in the target language rather than mother tongue. In the group discussion activity and presentation activity, the teacher communicated with students to give hints or correct errors. In translation tasks, students were required to read the whole paragraph to find moves before translating rather than translate sentences one by one.

\section{Conclusion}

Based on the empirical study, it can be proved that CLIL students have been found to be typically more engaged than students in regular second language teaching programs, due to the authenticity of the content that drives the learning experience. Previous studies don't involve the implementation of CLIL in EAP teaching and learning. The current research can well fill in the blank in this field. As proven in the research, CLIL motivates the doctoral students to acquire a deeper understanding of the purposes and strategies in learning EAP. Certain tasks and activities combining participants' discipline content and language are expected to be designed in CLIL classrooms. However, there are still some limitations. As the participants in the current research were not from the same major, some tasks cannot cover all the discipline content from different majors. Moreover, the participants were doctoral candidates from Dalian University of Technology. Therefore, further researches can be conducted under the context where CLIL is implemented in the classes of the students who come from the same major. The participants should include more candidates from various universities.

\section{References}

Christine Dalton-Puffer (2009). Content and language integrated learning: evidence from research in Europe. (1st ed.). Salisbury: Short Run, (Chapter 11).

Coyle, D (2007). Content and language integrated learning: towards a connected research agenda for CLIL pedagogies. The International Journal of Bilingual Education and Bilingualism. 10, 543-562.

Creswell, J.W. (2007). Qualitative Inquiry and Research Design: Choosing among Five Approaches. (2nd ed.). Thousand Oaks: Sage, (Chapter 3).

Izaskun Villarreal Olaizola \& Maria del Pilar Garcia Mayo (2009). Content and language integrated learning: evidence from research in Europe. (1st ed.). Salisbury: Short Run, (Chapter 9).

Julieta Ojeda Alba (2009). Content and language integrated learning: evidence from research in Europe. (1st ed.). Salisbury: Short Run, (Chapter 8).

Ken Hyland (2008). Genre and academic writing in the discipline. Language Teaching. 41, 62-543.

María del Pilar Agustin Llach (2009). Content and language integrated learning: evidence from research in Europe. (1st ed.). Salisbury: Short Run, (Chapter 7).

Maria Martinez Adrian \& M. Juncal Gutierrez Mangado (2009). Content and language integrated learning: evidence from research in Europe. (1st ed.). Salisbury: Short Run, (Chapter 10). 
DUT, (2008), Master's and doctoral degrees awarding rules of Dalian University of Technology. [Online] Available: http://www.doc88.com/p-396369139023.html (July, 2008)

Rachel Whittaker \& Ana Llinares (2009). Content and language integrated learning: evidence from research in Europe. (1st ed.). Salisbury: Short Run, (Chapter 12).

Rosa María Jiménez Catalán \& Yolanda Ruiz de Zarobe (2009). Content and language integrated learning: evidence from research in Europe. (1st ed.). Salisbury: Short Run, (Chapter 5).

Soraya Moreno Espinosa (2009). Content and language integrated learning: evidence from research in Europe. (1st ed.). Salisbury: Short Run, (Chapter 6).

Cai Jigang (2012). A study of CET orientation against the background of the internationalization of higher education. Journal of Foreign Languages. 1, 69-76.

Wang Wei (2013). Understanding and explaining CLIL and CLIL in China. English Square. 8, 97-100. 